\title{
Ópera y masonería: El Cántico fúnebre de José María Velásquez
}

\author{
Opera and Freemasonry: \\ The Funeral Canticle of José María Velásquez
}

\begin{abstract}
Juan de Dios López Maya
Doctor en Humanidades, master en Musicología Latinoamericana y licenciado en Composición Musical. Profesor jubilado de la Universidad Experimental de las Artes, Venezuela. Correos electrónicos: jddlmster@gmail.com y jddlm@,hotmail.com
\end{abstract}

DOI: http://dx.doi.org/10.15517/rehmlac.v8i2.25775

Fecha de recibido: 8 de octubre de 2016 - Fecha de aceptación: 12 de noviembre de 2016

Palabras clave

Músicos venezolanos del siglo XIX; Francisco Conde; Juan José Conde; ritos funerarios

Keywords

Venezuelan musicians of the Nineteenth Century; Francisco Conde; Juan José Conde; funeral rites

\section{Resumen}

El Cántico Fúnebre es una obra para tenor y orquesta escrita por el compositor venezolano del siglo XIX José María Velásquez con texto del político y escritor Francisco Conde. El Cántico fue escrito para los funerales de Juan José Conde, prócer de la Independencia y uno de los fundadores de la masonería local. Los rasgos más particulares de esta obra son la marcada influencia operística que posee la música y las referencias simbólicas masónicas del poema. Este artículo ofrece, en primer lugar, una visión de la ópera en Latinoamérica y su utilización como instrumento emulador de la cultura europea. Luego se estudia el proceso mediante el cual la ópera fue penetrando el ritual masónico hasta manifestarse plenamente en la ceremonia fúnebre y, finalmente, como las élites gobernantes, integradas en su mayoría por miembros de la orden y las clases medias, adoptaron a la ópera como uno de sus principales valores culturales.

\begin{abstract}
Cántico Fúnebre is a musical piece for tenor and orchestra written by nineteenth century Venezuelan composer Jose Maria Velasquez with lyrics by the politician and writer Francisco Conde. Cántico was written for the funeral of Juan Jose Conde, an independence leader and one of the founders of the local Masonry. The particular features of this piece are the remarkable influence of opera and the Masonic symbolism in the poem. This article provides, firstly, a vision of opera in Latin America and its use as a tool to emulate European culture. Then, it considers the process by which the opera penetrated Masonic rituals until fully manifested in the funeral ceremony, and finally, how the ruling elites, composed mostly of members of the order and the middle classes, adopted appreciation of opera as one of their main cultural values.
\end{abstract}

\section{Introducción}

El Cántico Fúnebre, del compositor venezolano del siglo XIX José María Velásquez, es una obra para tenor y pequeña orquesta que fue escrita especialmente para la 
ceremonia mortuoria de Juan José Conde. Era Conde un destacado masón, prócer de la Independencia venezolana y hombre público relevante de aquel entonces. Esta composición, escrita hacia 1848, es la partitura masónica más antigua que hay en nuestros fondos y uno de sus características más notables es que posee una marcada influencia operística.

Analizando otras obras masónicas venezolanas del siglo XIX, revisando la prensa de la época y la documentación masónica disponible, nos hemos percatado de que la influencia operística se extendió a toda la música que se tocaba en las logias y se hizo cada vez más notable a medida que avanzaba el siglo. Este sonido masónico-operístico se convirtió finalmente en sinónimo de cultura y buen gusto entre los masones y sus allegados.

Este artículo tiene un doble enfoque, el primero es musicológico, pues describe el estilo y morfología del Cántico como una obra musical y las acusadas influencias en ella de un género esencialmente europeo como lo es la ópera. El segundo enfoque es histórico,

pues hace notar que la ópera ayudó a consolidar un modelo de prohombre del siglo XIX, el cual está plasmado en la figura de "el masón" como prototipo del individuo con ideales progresistas y comportamiento liberal. Este personaje es común entre las sociedades occidentales del siglo antepasado y en Venezuela tuvo un marcado protagonismo en las esferas del poder político, económico y profesional.

\section{La ópera como uno de los ejes de la vida social en las clases altas y medias del siglo XIX}

En el siglo XIX la ópera fue utilizada como un instrumento civilizador. Ella ayudó a la burguesía a adquirir los modales cortesanos y satisfacer sus pretensiones aristocráticas. Las grandes ciudades rivalizaban entre si construyendo costosos teatros que albergaban a gran número de personas y estaban equipados con modernos escenarios y fosos para las orquestas. Para emular a las grandes ciudades, las pequeñas se esforzaban en construir sus propios teatros y fomentar la actividad operística. Una ciudad no estaba completa si no contaba con un teatro en donde se pudiera presentar ópera con regularidad.

La ópera era también un espacio heterogéneo, en el participaban compositores, directores de orquesta, instrumentistas, empresarios, periodistas, compañías de cantantes, dueños y directores de teatro, novelistas, libretistas, escenógrafos y un gran número de profesionales de otros oficios. Las giras de las compañías de ópera en el siglo XIX crearon el primer ejemplar del llamado star system: el cantante virtuoso o divo. Este personaje es el antepasado del rock star, o el actual ídolo pop.

Algunas veces la ópera, a través del libreto y la música, se convertía en herramienta política, casi siempre al servicio de la creación o confirmación de valores nacionales. Así sucedió con la obra de Verdi Nabuco y su famoso coro Va, pensiero, que se transformó en 
un ícono del llamado Risorgimento italiano; proceso que, entre 1820 y 1870, concretó la unificación casi completa de la península bajo el gobierno del rey Víctor Manuel.

También en Latinoamérica, y casi simultáneamente con Europa, la ópera cumplió el papel de agente civilizador y promotor de valores nacionalistas. Nuestras élites veían en ella un modelo de la cultura y la civilización que deseaban imitar. Entre Nabuco y las primeras óperas nacionalistas americanas hay escasas tres décadas de separación. Por supuesto, la mayor parte del repertorio que se escuchaba en nuestras ciudades estaba conformado por los grandes éxitos de los compositores italianos y franceses. Pero las compañías de ópera que venían del viejo continente estaban integradas básicamente por cantantes y empresarios. Para abaratar los costos, estas compañías hacían uso de las orquestas y directores locales. Las partituras, a veces manuscritas, que las compañías compraban o alquilaban en Europa, eran copiadas aquí por nuestros músicos. No sabemos si se hacía con el consentimiento de dichas compañías o clandestinamente, pero lo cierto es que en muchos archivos latinoamericanos hay abundantes copias de óperas europeas copiadas a mano por músicos locales.

\section{Masonería y ópera en Latinoamérica}

Al igual que en Europa, muchos periódicos latinoamericanos contaban con especialistas en crítica operística, los propios editores estaban frecuentemente a cargo de esa función. La pasión por la ópera entre las clases altas y medias fue tan intensa aquí como del otro lado del océano y la masonería, que en el siglo XIX estaba estrechamente vinculada con las élites, no podía ser ajena a esto. En muchos casos, fueron masones poderosos quienes, a título personal, fomentaron la ópera, en otros, fue la propia masonería como institución que se dedicó a promocionarla, casi siempre con carácter filantrópico.

Los casos más emblemáticos de masones poderosos que estuvieron involucrados con la actividad operística son Porfirio Díaz en México y Domingo Faustino Sarmiento en Argentina y Chile. En Venezuela cumplieron el mismo papel los presidentes José Antonio Páez y Antonio Guzmán Blanco. Los cuerpos masónicos, tal como los grandes orientes, de mayor capacidad financiera y organizativa que las logias, se ocuparon de promover y organizar operas con carácter filantrópico. En Venezuela, el Gran Oriente participaba con frecuencia en estas actividades, logrando de esta manera una buena dosis de aprobación social en los estratos altos y medios.

\section{La masonería y el poder en la Venezuela del siglo XIX}

El control que los masones ejercieron sobre el poder político y económico en la Venezuela del siglo XIX fue muy notable. El quincenario masónico Sol de América del $1^{\circ}$ de junio de 1890 publica una lista de treinta y ocho presidentes de la República que 
pertenecieron a la orden (ver Apéndice 2). Lo abultado de la lista se debe a que en ella aparecen no solo los que ejercieron de manera titular la primera magistratura, sino además todos aquellos que de manera interina o circunstancial ocuparon temporalmente el cargo. Otro aspecto notable de la lista es la abundancia de altos grados del escocismo entre los nombrados; de los treinta y ocho un total de veinticinco detentaban el $33^{\circ}$ grado, uno el $32^{\circ}$, tres el $30^{\circ}$ y siete el $18^{\circ}$.

Estos presidentes por lo general se rodeaban de otros masones, integrándolos a sus respectivos gabinetes ministeriales, colocándolos en las gobernaciones de provincias y en los comandos altos y medios de las fuerzas armadas. La mayoría de ellos tenía una vida masónica activa, incluso durante el ejercicio de su presidencia. Para ilustrar esto mencionaremos los casos de José Antonio Páez, quien durante su segundo mandato presidencial (1839-1843) funda, junto a su ministro de Relaciones Interiores Diego Bautista Urbaneja, el Supremo Consejo del Grado $33^{\circ}$ Para la República de Venezuela, siendo electo además como su primer Soberano Gran Comendador ${ }^{1}$.

El presidente en ejercicio José Tadeo Monagas es nombrado Gran Maestro del Gran Oriente de Venezuela en 1856, durante su segundo mandato ${ }^{2}$. Otro tanto ocurre con los presidentes en ejercicio Antonio Guzmán Blanco, quién se hace nombrar Gran Protector de la Masonería Venezolana en 1876, una especie de presidencia vitalicia la cual ejerció hasta $1888^{3}$, y Raimundo Andueza, nombrado Gran Maestro del Gran Oriente Nacional ${ }^{4}$ en 1891.

En el ámbito empresarial mencionaremos también algunos casos emblemáticos. Comenzando con Isaac Pardo, hombre de negocios proveniente de Hamburgo pero de origen luso-sefardí, quien fue fundador del Primer Banco de Venezuela y la primera compañía de telégrafos nacionales ${ }^{5}$. Pardo fue un prominente masón, fundador de la logia Esperanza $n^{\circ} 7$ y Gran Maestro del Gran Oriente Nacional ${ }^{6}$. También fueron importantes empresarios, pero en el ámbito editorial, los masones León van Praag y George Corser, ambos de origen judío y provenientes de Curazao. Van Praag publicó durante muchos años una Guía de Caracas $^{7}$, la cual fue precursora de la publicidad gráfica en nuestro país y

\footnotetext{
${ }^{1}$ José Antonio Ferrer Benimelli, "Masonería", en Diccionario de Historia de Venezuela (Caracas: Fundación Empresas Polar, 1997), vol. 3, 76.

${ }^{2}$ Discurso Traz $\therefore$ en la Inst.: del Gr.: Or: Nac.: Caracas: 1856.

${ }^{3}$ Cuadro de las DD $\therefore$ OOf $\therefore$ y demás miembros de la Resp $\therefore$ Log.: Regeneración $\mathrm{N}^{\circ} 40$ al Or.: de Caracas 1882

${ }^{4}$ Instalación del Gr:: Or:: Nac: de los EE.UU. de Venezuela, El Sol de América 47 (24 de junio de 1891), 12 .

${ }_{6}^{5}$ María Ramírez, El otoño luminoso de Isaac Pardo (Caracas: Monte Ávila, 1999), 4-5.

${ }^{6}$ Juan de Dios López Maya, "Esperanza n7 (1854-1869). Quince años en la vida musical de una logia caraqueña", Anuario GHRIAL 6 (2012): 173-204.

${ }^{7}$ León van Praag, Guía de Caracas para 1891-1892 (Caracas: Tipografía El Cojo, 1892).
} 
Corser, por su parte, era el dueño de una de las imprentas más modernas e importantes de Caracas durante las décadas de 1840 a $1870^{8}$.

\section{Músicos y masones}

Junto con los masones detentadores del poder político y económico, había en las logias venezolanas una notable cantidad de músicos importantes. Tanto en Caracas como en las ciudades de la provincia era frecuente encontrar masones a cargo de la dirección de bandas y orquestas. El caso más emblemático es el de la Banda Marcial Caracas, la cual, desde su fundación en 1864 hasta 1946, fue dirigida casi ininterrumpidamente por masones; entre ellos José Ángel Montero, Federico Villena, Francisco de Paula Magdaleno y Pedro Elías Gutiérrez ${ }^{9}$. En la provincia podemos citar al propio Federico Villena, fundador de la Banda Piar de Ciudad Bolívar ${ }^{10}$ y a Benigno Rodríguez Bruzual, director de la Banda de Cumaná $^{11}$.

Muchos de ellos eran también compositores y profesores en conservatorios o a domicilio. Las fuentes de ingreso para un músico venezolano en el siglo XIX eran las bandas, la Iglesia, el teatro, el salón de baile y la docencia. Como los ingresos por estas actividades eran escasos, casi todos ellos se veían en la necesidad de ejercer varios o todos estos oficios simultáneamente. Los músicos masones estaban, además, a cargo de la música en las logias y muchos cuadros logiales impresos dan fe de la existencia de Columnas de Armonía en su seno, las cuales estaban integradas y dirigidas por conocidos músicos locales. Como ejemplo citamos a las logias Perfecta Armonía de Cumaná y Regeneradores de Maracaibo ${ }^{12}$.

Se formó así un profesional de la música con características muy particulares: para pertenecer a una banda, generalmente dependiente del Ministerio de Guerra y Marina, había que poseer un grado militar y cierta formación castrense, además de conocimientos de música militar. Para dirigir la capilla de una iglesia había que componer obras litúrgicas en latín y tocar el órgano. Trabajar en el teatro familiarizaba a los músicos con la ópera, la zarzuela y los idiomas italiano y francés. El salón de baile también tenía sus exigencias; el músico debía conocer los géneros de moda en Europa además de los bailes locales. La enseñanza llevó a muchos de ellos a escribir y publicar textos pedagógicos y, finalmente,

${ }^{8}$ Almanaque para el año de 1851: arreglado para el meridiano de Caracas. Caracas: Imprenta de George Corser, 1851.

9 Jesús Ignacio Pérez Perazzo, El Maravilloso Mundo de la Banda (Caracas: Cuadernos Lagoven, 1989), 7578.

${ }^{10}$ Anibal Ruíz, Boceto biográfico del Maestro Federico Villena (Caracas: s.e., 1898).

${ }^{11}$ Felipe Saingiorgi, "Rodríguez Bruzual, Benigno", en: Enciclopedia de la Música en Venezuela. Caracas: Fundación Biggot, s.a.

${ }^{12}$ Cuadro de las DD.., OOf: y demás miembros de la Res.: Log.: Perfecta Armonía $n^{\circ} 2$ al Or:. de Cumaná para el año de 1882 e $\therefore$ v $\therefore$.

Cuadro de las DD:., OOf: y demás miembros de la Res Log Regeneradores $n^{\circ} 6$ al Or: de Maracaibo para el año de 1879 e.: $\therefore$. 
para tocar en las logias, había que ser iniciado y dominar el ritual. Esta vasta formación se adquiría casi siempre de manera ecléctica: una parte en la familia, otra en alguna institución, y la mayor parte empíricamente.

\section{La ópera en las ciudades latinoamericanas en los siglos XVIII y XIX}

En Latinoamérica la ópera siguió un camino muy parecido al de Europa. Ya en tiempos coloniales había en nuestro continente actividad operística. México, por su condición de capital virreinal y gran ciudad, tuvo actividad muy temprana en este sentido. En 1711 el compositor Manuel de Zumaya compone y estrena La Partenopé, la primera ópera mexicana y la segunda más antigua de Latinoamérica ${ }^{13}$. Siendo la primera La Púrpura de la Rosa, del compositor Peruano Ramón de Torrejón y Velazco y libreto de Calderón de la Barca. La Púrpura de la Rosa fue estrenada en Lima en 1701.

En el siglo XIX el compositor Aniceto Vega de Vilar, escribe lo que se considera la primera ópera nacionalista en México: Guatemotzin ${ }^{14}$, la cual fue estrenada en el Teatro Nacional de Ciudad de México en 1871. Otro compositor mexicano famoso por sus óperas fue Melesio Morales, su ópera Anita, también de corte nacionalista, fue escrita en 1910, pero nunca fue estrenada en vida del compositor ${ }^{15}$.

En Brasil el primer teatro de ópera, la Casa da Opera, fue construido en Río de Janeiro entre 1747 y 1748. En 1763 la corte virreinal se trasladó de Salvador de Bahía a Río y la corte real portuguesa lo hizo en 1808. Con este doble apoyo, la ópera se consolidó en Río y en otras ciudades brasileñas a principios del siglo XIX. La primera ópera compuesta por un brasileño fue $A$ Noite de São João, de Elías Lobo. Fue escrita en 1859 y estrenada en 1860 en el desaparecido teatro São Pedro de Alcântara, en Rio ${ }^{16}$.

Carlos Gomes, nacido en 1836, compuso Il Guarany la primera ópera brasileña considerada como nacionalista, en 1870 . Gomes estudiaba en Italia para ese entonces y la obra fue estrenada en Florencia ese mismo año. Il Guarany se convirtió en un éxito

\footnotetext{
${ }^{13}$ Hugo Roca Joglar, "La Partenopéde Manuel de Sumaya”, en Pro ópera (noviembre-diciembre 2011 [citado el 31 de marzo de 2016]: disponible en http://www.proopera.org.mx/pasadas/novdic 3/Revista/3840aniversario-nov11.pdf

${ }^{14}$ Adrián Figueroa, "Hallan diez partituras del compositor Aniceto Ortega", en Crónica.com.mx (13 de abril de 2010 [citado el 31 de marzo de 2016]: disponible en http://www.cronica.com.mx/especial.php?id tema $=1237 \&$ id nota $=499957$

15 "Llega la ópera "Anita" de Melesio Morales al Foro Cultural Chapultepec", en INBA Boletín 483 (9 de abril de 2014 [citado el 31 de marzo de 2016]: disponible en http://www.inba.gob.mx/Prensa/SearchByDisciplina?disciplina=3

${ }^{16}$ Gisele Scaveli, "Elías Lobo, um ituano imortal”, en Revista Regional (s/f [citado el 31 de marzo de 2016]: disponible en http://revistaregional.com.br/portal/?p=4846
} 
internacional, pues se representó en varias ciudades europeas y americanas entre 1872 y 1884. En diciembre de 1883 recibió su primera representación en Rio ${ }^{17}$.

En Buenos Aires, la primera representación completa de una ópera tuvo lugar en 1826 con Il Barbieri di Siviglia de Rossini. Pero fue apenas en 1897 cuando el compositor Arturo Beruti compuso Pampa, considerada la primera ópera nacionalista en ese país ${ }^{18}$. Domingo Faustino Sarmiento, que llegaría a ser presidente de Argentina y era también un destacado masón, escribió para el periódico chileno El Progreso, fundado por el mismo en 1842, varios artículos en donde consideraba a la ópera como un agente civilizador y un vehículo de difusión de ideas democráticas. Durante su presidencia (1868-1874) la ópera en Buenos Aires y otras ciudades del país recibió un apoyo considerable.

\section{La ópera en Venezuela durante el siglo XIX}

Caracas, y otras ciudades venezolanas como Valencia, Maracaibo y Cumaná, eran pequeñas y modestas en comparación con Ciudad de México, Río o Buenos Aires. Sin embargo, la actividad teatral y operística fue intensa y comenzó muy temprano en el siglo XIX. Las primeras noticias de prensa sobre representaciones de ópera en Caracas datan de 1808. Ese año una compañía francesa protagonizó una temporada con ocho diferentes operas. La orquesta estaba integrada por conocidos músicos caraqueños y dirigida por Juan José Landaeta, reconocido como el autor de la música del himno nacional.

El teatro lírico fue perjudicado por la guerra de Independencia (1810-1823) y posteriormente por los sucesos que condujeron a la separación de Venezuela de Colombia, conocidos con el nombre histórico de "La Cosiata" (1826-1829). En 1830 Venezuela comienza su vida como nación independiente. El período que va desde 1830 hasta 1898 es conocido como la "Venezuela Republicana". Su primer presidente, el general José Antonio Páez, gobernó el país, con algunas interrupciones, entre 1830 y 1863. Era un gran melómano y amante de la ópera, tocaba varios instrumentos y cantaba de memoria arias y canciones tradicionales venezolanas. Páez fue el principal suscriptor de la "Sociedad Filarmónica" la primera en su tipo en la Venezuela Republicana. Esta fue creada en Caracas en 1831. En 1836, la Sociedad tuvo a su cargo la representación de la Gazza Ladra e Il Barbieri di Siviglia de Rossini, introduciendo así el gusto por la ópera italiana en la ciudad y posteriormente en la provincia.

Páez, al igual que Atanasio Bello, uno de los fundadores de la Sociedad Filarmónica, era un destacado masón. No solo fundó varias logias, además fue cofundador en Caracas del Consejo Supremo Confederado del Grado $33^{\circ}$ para la República de

\footnotetext{
${ }^{17}$ Verónica Zárate Toscano y Serge Gruzinsky, “Opera, imaginación y sociedad. México y Brasil, siglo XIX. Historias conectadas: Idelgonda de Melesio Morales e Il Guarany de Carlos Gomes", Historia Mexicana LVIII, no. 2 (2008): 803-860.

${ }_{18}$ Melanie Plesch y Geranrdo Huseby, La música argentina en el siglo XX (Buenos Aires: Editorial Sudamericana, 2014), tomo II. 33.
} 
Venezuela, del cual fue su primer Gran Comendador ${ }^{19}$. Se inauguraba así una tradición que se mantuvo a lo largo del siglo XIX: el vínculo entre la presidencia de la República, la ópera y la masonería. Años más tarde, durante su exilio en Buenos Aires (1868-1871), Páez hizo gran amistad con el presidente Domingo Faustino Sarmiento, a quién había conocido en Nueva York ${ }^{20}$. Ambos compartían la pasión por la ópera y el grado $33^{\circ}$.

La primera ópera escrita por un venezolano fue El Maestro Rufo Zapatero de José María Osorio, en el año de 1845. Osorio, aunque era caraqueño, vivió e hizo carrera musical en la pequeña ciudad de Mérida, en donde compuso, montó y público, en su propia litografía, esta ópera. Pero fue recién en 1873 cuando José Ángel Montero estrenó en el Teatro Caracas su ópera Virginia, la cual fue considerada por mucho tiempo como la primera ópera cuya música era de un autor venezolano.

José Ángel Montero era calificado como el músico más importante de su tiempo y hoy en día lo reconocemos como el más destacado de todo el siglo XIX ${ }^{21}$. Pero Montero no era un compositor de óperas; la mayor parte de su producción está integrada por zarzuelas, música de salón y música litúrgica católica. El apogeo de la carrera musical de Montero coincidió con la primera presidencia de Antonio Guzmán Blanco, quién, al igual que Páez, tuvo en sus manos las riendas del poder, con algunas breves interrupciones, entre $1870 \mathrm{y}$ 1888. Todo indica que Montero escribió Virginia por encargo del Ejecutivo Nacional, y seguramente a pedido del propio Guzmán Blanco, a quién la obra está dedicada.

El gobierno de Guzmán Blanco, usando el lema "Orden y Progreso", acometió una serie de reformas legales, económicas y educativas de claro corte positivista. Su proyecto de trasformación arquitectónica de Caracas estaba inspirado en la París del Imperio Liberal de Napoleón III, que Guzmán conocía bien por haber vivido en la Ciudad Luz durante algunos años de ese período. En el marco de esta reforma no podía faltar un teatro al estilo europeo, este fue inaugurado en 1881 con el nombre de Teatro Guzmán Blanco (Hoy Teatro Municipal de Caracas). Para el estreno se contrató una compañía de ópera que interpretó Il Trovatore de Verdi. El afrancesamiento en las costumbres de las élites venezolanas de ese entonces y hasta principios del siglo XX, es atribuido a las políticas de los gobiernos guzmancistas.

Virginia fue utilizada, por el gobierno de Guzmán, para demostrar al mundo que en Venezuela se podía componer y montar una ópera al mejor estilo italiano. El libreto, perteneciente a Domenico Bancalari, está ambientado en Roma en el año 448 A.C. y es el

\footnotetext{
${ }^{19}$ Hello Castellón, Guía Histórica de la Masonería Venezolana (Caracas, LITOJET, 1975), 61-62.

${ }^{20}$ Juan de Dios López, "El Cuaderno de Música de José Antonio Páez", El Desafío de la Historia 5, no. 31 (s.a.): $22-25$.

${ }^{21}$ José Ángel Montero es representante de un caso típico entre los músicos venezolanos de la época: ser masón y músico. Era sobrino de Atanasio Bello y del músico Bernardino Montero, ambos masones. También pertenecieron a la Orden y eran músicos su hermano Ramón Montero, su sobrino Manuel Montero, hijo de Ramón y Manuel Montero y Carlos Montero, nietos de Ramón. Un linaje de cuatro generaciones que va desde principios del XIX hasta principios del XX.
} 
típico drama decimonónico, en donde la protagonista muere a causa de un amor prohibido $^{22}$. Montero no volvió a escribir más nunca una ópera en italiano. Algunos elementos nacionalistas, o más bien costumbristas, aparecen en sus zarzuelas y se limitan a la inclusión de géneros bailables, típicos de los salones venezolanos de la época. También algunos libretos usados por Montero pertenecen a autores venezolanos con la misma tendencia costumbrista, como por ejemplo la zarzuela Doña Irene o la Política en el Hogar (1876), escrito por Francisco Tosta García ${ }^{23}$, uno de los hombres fuertes de Guzmán ${ }^{24}$.

\section{Imagen 1}

Portada del libreto de Virginia

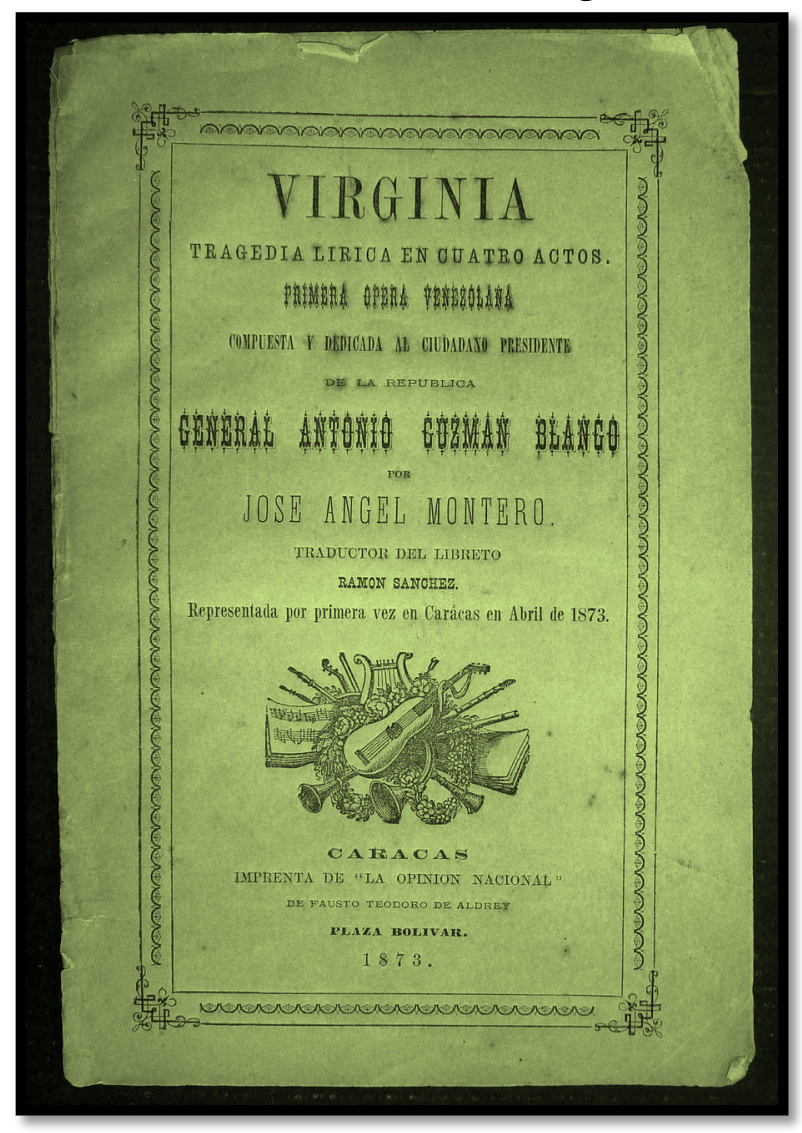

Fuente: Colección BNV. Fotografía de Juan de Dios López.

\footnotetext{
${ }^{22}$ José Ángel Montero, Virginia, tragedia lírica en cuatro actos (Caracas, Imprenta de la Opinión Nacional, 1873).

${ }^{23}$ José Ángel Montero y Francisco Tosta García, Doña Irene o la política en el Hogar (Caracas, Imprenta de la Concordia, 1876).

${ }^{24}$ Además de general -héroe de la Guerra Federal- Tosta García se destacó como político, escritor y masón. Escribió una obra llamada Episodios Nacionales, imitando la obra homónima de Benito Pérez Galdós. En política fue diputado al Congreso, gobernador de una provincia y presidente encargado de la República. Como masón alcanzó el grado $33^{\circ}$.
} 


\section{La actividad musical dentro de las logias}

La costumbre, que comenzó en las las logias francesas durante el siglo XVIII ${ }^{25}$, de hacer entrar solemnemente en el templo a las dignidades ${ }^{26}$ al son de una marcha, parece haber sido el origen de los conjuntos instrumentales que se conocen con el nombre de columnas de armonía ${ }^{27}$ (colonne d'harmonie). El repertorio de las columnas de armonía se componía de marchas militares y fragmentos instrumentales provenientes de óperas que estaban de moda en ese momento. En sus comienzos las columnas estaban conformadas únicamente por instrumentos de viento, delatando su origen militar. A medida que discurría el siglo se incorporaron instrumentos provenientes del mundo sinfónico y operístico. Esto a consecuencia de la incorporación a las logias de individuos provenientes de las diferentes orquestas y teatros que proliferaron durante aquella época ${ }^{28}$.

En Inglaterra, con la publicación de las Constituciones de Anderson en 1723, se evidencia la naturaleza de las costumbres musicales en las logias inglesas. En ella aparecen, a manera de apéndice, cuatro canciones para el uso ritual, las cuales se consideran, hasta ahora, como los impresos musicales masónicos más antiguos. Estas canciones, tres de las cuales poseen letra y música escrita en partitura, están emparentadas con la tradición de los cantos colectivos, característicos de las cofradías y gremios medievales europeos, y también con el canto en las congregaciones religiosas, propio de las iglesias protestantes y anglicanas.

Las cuatro canciones, La Canción del Maestro, La Canción de los vigilantes, La Canción de los compañeros y La Canción de los aprendices, fueron traducidas a varios idiomas a lo largo de los siglos XVIII y XIX. La Canción de los aprendices, cuya sencilla música recuerda un canto de taberna, aun se canta en las logias inglesas, irlandesas, australianas y norteamericanas. Las identidades grupales suelen reforzarse con el canto colectivo y las canciones de las Constituciones constituyen un claro ejemplo de la aplicación de esta estrategia.

El paso siguiente en el desarrollo musical masónico fue la adopción del órgano, tanto en las logias inglesas como en las francesas. Este instrumento no solo enriquecía la majestuosidad de las tenidas, sino además permitía un ahorro considerable en el presupuesto de las logias, pues a finales del siglo XVII los instrumentistas empezaron a exigir el pago de sus servicios, especialmente cuando los prestaban a una logia que no era la propia ${ }^{29}$. De esta manera, aquellas logias, que podían comprar un órgano, enriquecieron

\footnotetext{
${ }^{25}$ Roger Cotte, La Musique Maconnique et sus Musiciens (Braine-le Comte: Edicions du Baucens, 1975), 38.

${ }^{26}$ Se llama así los miembros de una logia que desempeñan un cargo o han sido envestidos de una dignidad: venerable, secretario, orador fiscal, vigilante, etc.

${ }^{27}$ Cotte, La Musique Maconnique, 38.

${ }^{28}$ Cotte, La Musique Maconnique, 45.

${ }^{29}$ Cotte, La Musique Maconnique, 43, 47-49.
} 
notablemente la teatralidad de sus tenidas y desarrollaron un cierto parecido con la actividad litúrgica católica y protestante. Las agrupaciones instrumentales y los grandes coros quedarían reservados para tenidas importantes, y para las logias y cuerpos masónicos que, por su tamaño y relevancia, podían pagarlos.

En las colonias norteamericanas la masonería inglesa se extendió con notable rapidez durante el siglo XVIII. El uso del órgano y el canto colectivo fueron adoptados por aquellas logias y la tradición ha continuado hasta el presente. A principios del siglo XIX, ya formado los Estados Unidos, se publicaron varios cancioneros masónicos, casi todos en las ciudades de Boston y Nueva York ${ }^{30}$.

\section{La Música en las logias venezolanas}

En Venezuela, al igual que en otros países de Latinoamérica, la masonería se desarrolló a partir de los movimientos independentistas que se dieron a principios del siglo XIX. En 1824 se crea en Caracas la Gran Logia de la República de Colombia ${ }^{31}$, que agrupaba un total de dieciocho logias distribuidas por todo el territorio venezolano. La mayoría de estas logias, fundadas entre 1810 y 1823 , recibieron sus cartas patentes $^{32}$ de logias norteamericanas entre 1821 y 1823 . La Gran Logia de Maryland ${ }^{33}$, la Gran Logia de Nueva York y la Gran Logia de Pensilvania, fueron las principales promotoras de la legitimación y, al final, fue la Gran Logia de Nueva York, a través de su enviado plenipotenciario Joseph Cernau, que consolidó a las dispersos talleres dentro de la Gran Logia, además de conceder altos grados a los más eminentes líderes de la Independencia.

La masonería venezolana tuvo un período de decadencia luego de la separación de Venezuela de la Gran Colombia en 1830. Pero a partir de 1838 comienza a consolidarse nuevamente. Ese año se crea la Gran Logia de la República de Venezuela y en 1839 el Supremo Consejo del Grado $33^{\circ}$. A partir de ese momento la documentación relativa a la masonería es más abundante y variada. En la década de 1840 empiezan a publicarse cuadros logiales impresos (anteriormente eran manuscritos). De la década de 1850 los fondos contienen actas, papeles administrativos y folletería impresa y a partir de finales de la década de 1860 contamos también con prensa masónica.

Gracias a los cuadros hemos podido detectar la presencia de muchos músicos en las logias. Además, algunas logias incluían en los cuadros a los miembros de sus columnas de

\footnotetext{
${ }^{30}$ Juan de Dios López, "Columnas de armonía, la tradición musical masónica del siglo XVIII y su reflejo en las logias venezolanas del siglo XIX" (ponencia presentada en el VII Congreso español de musicología, Logroño, 2012 [citado el 5 de marzo de 2016]): disponible en http://www.sedem.es/es/catalogo.asp?cat=122

${ }^{31}$ En ese entonces la actual Venezuela, junto con Colombia y Ecuador, pertenecía a lo que los historiadores han llamado "La Gran Colombia".

${ }^{32}$ Documento que otorga una Obediencia y que garantiza la legitimidad de una logia o capítulo.

${ }^{33}$ En 1822 la Gran Logia de Maryland, ubicada en Baltimore, expidió un total de cinco cartas patentes. Las beneficiarias fueron Protectora de las Virtudes, Perfecta Armonía, Fraternidad Colombiana, Valor y Constancia y Unanimidad de Cartago. Cuatro de ellas aun funcionan en la actualidad.
} 
armonía, dando a entender que contaban con sus propias columnas y que no requerían la contratación de músicos masones pertenecientes a otras logias. Esto se verificaba especialmente en las ciudades que contaban con una sola logia, mientras que en Caracas y otras ciudades de mayor tamaño y con más de una logia, parece haber predominado la costumbre de contratar músicos pertenecientes a otros talleres.

Las actas y demás documentos administrativos y la folletería, nos han permitido determinar la frecuencia y la naturaleza de las actividades musicales dentro de las logias. En la prensa hemos conseguido numerosas referencias a actividades musicales en tenidas blancas $^{34}$ y también al patrocinio, con fines filantrópicos, de recitales y conciertos dentro y fuera de los templos. Veamos algunos ejemplos:

\section{CRONICA.}

Un gran concierto vocal e instrumental tendrá lugar en el templo Masónico de esta ciudad, la noche del 20 de los corrientes a las 8 y media, dedicado por el señor Ángel De Sanctis á los altos cuerpos de la masonería y a los cuerpos constituidos del Or: de Caracas. Tomarán parte en la velada la distinguida maestra señorita Sofía Limonta y señorita María Moreira y los profesores Régulo Berra, Manuel Pérez, Andrés Sosa, Pedro E. Gutiérrez, Andrés Delgado Pardo, Ignacio Bustamante, y el joven Rafael Saumell.

El programa elaborado para esta fiesta en que lucirá espléndidamente el arte, es selecto y variado. (La Opinión Nacional, 19 de mayo de 1891, n 6.490, pág. 3) SOLSTICIO DE VERANO

La Resp $\therefore$ Loj: Candor $\mathrm{n}^{\circ} 27$ al Or:: de San Fernando celebró con pompa inusitada la fiesta del Solsticio de Verano, según se verá por la revista que tomamos del Araucano (...)

Con la debida anticipación circuló un programa de la fiesta, y tarjeta de invitación para todos los actos públicos que iban a tener lugar en el Templo Masónico. También circuló una hoja conteniendo el himno masónico titulado "Elogio a la Amistad", para los entreactos y acompañado por la banda de música.

El programa constaba de nueve partes distribuidas así:

1.- Víspera. A las $12 \mathrm{~m}$ enarbolación de las banderas del templo y fuegos artificiales con profusión. Por la noche iluminación del edificio de la Lojia [Sic], cohetes y retreta por la Columna Filarmónica.

2.- Día 24, A las 8 am tres cañonazos en la parte frente al edificio. (...)

6.- Apertura de la tenida amenizada con la música y el Himno Masónico.

7.- Fiesta de adopción, o sea bautizo masónico de varios niños. (...)

(El Sol de América, 27 de julio de 1887, pág. 112)

FIESTA MASÓNICA

\footnotetext{
${ }^{34}$ Asambleas masónicas en las que se permite la presencia de profanos o no iniciados.
} 
La lojia [Sic] "Unanimidad" $\mathrm{n}^{\circ} 3$ abrió ayer sus misteriosas puertas para celebrar públicamente las fiestas de San Juan de verano y adoptar algunos luvetones. (...)

Poco después de las tres, la música dejó oír sus gratas armonías y se dio principio a la simbólica solemnidad (...) todos los actos fueron celebrados al compás de la música y revistieron la más augusta y majestuosa pompa. (...)

En medio de aquel concierto de gratas satisfacciones, se cantó un himno música de Federico Villena y letra del poeta Casto R. López, que produjo en el ánimo de todos las más gratas impresiones. (El Sol de América, 28 de junio de 1887, pág. 103)

TERREMOTO DE ANDALUCÍA

Tenemos noticias de que la $\mathrm{M} \therefore \mathrm{R} \therefore \mathrm{G} \therefore$ Loj $\therefore$ trata de organizar una función teatral en el Teatro Caracas a beneficio de a los desgraciados que han sido víctimas de los terremotos en Andalucía (España). Deseamos que dicha función tenga lugar y excitamos a concurrir a ella a todos nuestros hh. para que los resultados sean positivos. Ejercerán la caridad deleitándose ${ }^{35}$.

Las partituras, manuscritas e impresas, han servido para formarnos una idea del tipo de música que se utilizaba, tanto en las tenidas rituales como en las blancas. La más antigua de estas partituras, escrita en 1848, es precisamente el Cántico fúnebre de José María Velásquez, objeto de este artículo.

Analizando esta información hemos podido determinar que en las logias venezolanas se practicaba más el estilo francés, es decir, el uso de las columnas de armonía puramente instrumentales, que el estilo inglés, en donde predominaba el canto colectivo y el órgano. A pesar de que nuestras primeras logias, como hemos dicho, recibieron sus cartas patentes de logias norteamericanas, y que el Rito Escocés Antiguo y Aceptado fue predominante, en lo musical se aprecia el uso de agrupaciones instrumentales pequeñas, música proveniente de óperas de moda, marchas y algunas piezas propias de compositores locales. Sin embargo, hemos conseguido algunas noticias acerca de la compra de órganos y también evidencias de la práctica del canto colectivo en las logias venezolanas ${ }^{36}$.

\section{José María Velásquez}

José María Velásquez fue uno de los músicos más conocidos en la Caracas de mediados del siglo XIX. Provenía de un linaje de músicos, pues su padre y su abuelo, conocidos en la historia como José Francisco Velásquez el joven y el viejo respectivamente, habían tenido una destacada actividad como compositores a finales del siglo XVIII y comienzos del XIX. No sabemos su fecha exacta de nacimiento, pero tenemos una pista: su

\footnotetext{
${ }^{35}$ La Estrella Flamigera 13 ( $1^{\circ}$ de marzo de 1885), 200.

${ }^{36}$ López Maya, “Esperanza nº 7 (1854-1869)", 173-204.
} 
padre, José Francisco Velásquez el joven, murió en $1822^{37}$, por lo que suponemos que José María vino al mundo en algún momento de la década de 1810 o principios de la de 1820 . La muerte de José María se produjo en algún momento de finales de 1883, lo cual deducimos de su obituario, que se publicó en el quincenario masónico La Abeja con fecha $1^{\circ}$ de enero de $1884^{38}$.

Tuvo una actuación destacada tanto en la música como en la masonería. Su vida musical se desarrolló en diferentes escenarios: en orquestas de baile, en la ópera y en la Iglesia. Su instrumento era la viola y además se desempeñaba como cantante de coro ${ }^{39}$. También se dedicó a la composición, como lo atestiguan algunas obras religiosas y por supuesto el Cántico Fúnebre. La mayoría de los manuscritos de su autoría, que reposan en la Biblioteca Nacional de Venezuela, son transcripciones de oberturas de óperas conocidas, casi todas de Rossini.

Otro aspecto importante de su actividad musical es el hecho de haber sido presidente del Gremio de Músicos del Distrito Federal. En efecto, en los documentos relativos a la celebración de Centenario del Natalicio del Libertador Simón Bolívar (1883), hemos encontrado una carta dirigida "Al ciudadano José María Velásquez, presidente del Gremio de Músicos", en donde se le informa que la participación del gremio que preside ha sido autorizada por la directiva de la Comisión Centenaria a participar en los festejos ${ }^{40}$. Esta carta es, por cierto, una de las primeras noticias que se tiene de la práctica gremial musical en la Venezuela Republicana.

Fue un masón muy notable. Aparece como fundador de la logia América en un cuadro logial fechado en 1843. Ya para ese momento poseía el grado $18^{\circ}$ del Rito Escoces Antiguo y Aceptado. Este cuadro, perteneciente a la Academia Nacional de la Historia, es uno de los más antiguos que hay en Venezuela ${ }^{41}$. Más adelante, al desaparecer la logia América como consecuencia del cisma masónico de $1851^{42}$, Velásquez se afilió a la logia Prudencia. En un cuadro de los miembros de dicha logia, del año de 1856 , aparece ya con el grado $33^{\circ}$, siendo posiblemente el primero y uno de los pocos músicos venezolanos del siglo XIX en alcanzar este grado ${ }^{43}$. El segundo cuadro en antigüedad que se encuentra en nuestros fondos pertenece al capítulo Unión Venezuela $n^{\circ} 1^{44}$, está fechado el 9 de mayo de 1844 y en él

\footnotetext{
${ }^{37}$ Calcaño, La ciudad y su música, 68.

38 La Abeja, "Duelo a la memoria del M $\therefore$ I $\therefore$ H $\therefore$ Gr.: Insp $\therefore$ Gral $\therefore$ José María Velásquez" (1 de enero de 1884), 237-238.

${ }^{39}$ Calcaño, La ciudad y su música, 311.

40 Antonio Leocadio Guzmán, "Junta Directiva del Centenario del Libertador n 400", Archivo General de la Nación, sección Centenario del Libertador, Caracas, 20 de enero de 1883, legajo dos, folio 2 r.

41 "Cuadro de las DD.: Ofic: $\mathrm{y}$ demás miembros de la Resp $\therefore$ Log.: América n ${ }^{\circ} 17$ en el año de 1849", Academia Nacional de la Historia, sección Arístides Rojas, (hoja suelta)

${ }^{42}$ Eloy Reverón, Cisma masónico, Caín y Abel son hermanos (Caracas: IVEM, 1996), 17-18.

43 "Cuadro de las DD $\therefore$ Ofic. y demás miembros de la Resp $\therefore$ Log.: Prudencia ${ }^{\circ}{ }^{40}$, al Or.: de Caracas en el año de 1856", Colección Juan de Dios López Maya.

${ }^{44}$ Es también el cuadro capitular más antiguo que se conoce en Venezuela.
} 
aparece el nombre de otro destacado músico caraqueño, Atanasio Bello Montero, también con el grado $18^{\circ 45}$.

Revisando los cuadros logiales de la época, encontramos que las logias estaban integradas principalmente por altos oficiales de las fuerzas armadas. Muchos de ellos eran próceres o hijos de próceres de la Independencia. Junto a ellos figuran altos funcionarios públicos y miembros de la naciente burguesía comercial que se estaba formando en las principales ciudades. Qué un músico, el cual ejercía un oficio "menor" en aquella sociedad, poseyera el grado $33^{\circ}$, es un indicativo del prestigio de Velásquez y de la pluralidad que existía ya pare ese momento en la institución ${ }^{46}$.

\section{El poema de Francisco Conde}

En el último folio de la partitura general del Cántico Fúnebre de José María Velásquez puede leerse lo siguiente: "Partición del cántico fúnebre en las exequias qu la $\mathrm{R} \therefore \mathrm{L} \therefore$ Concordia $\mathrm{n}^{\circ} 6$ celebró a la memoria del $\mathrm{M} \therefore \mathrm{I} \therefore \mathrm{H} \therefore$ Juan José Conde. Letra del h $\therefore$ Francisco Conde Música del h.: José María Velásquez" ${ }^{\star 4}$.

Juan José Conde, el occiso, era un representante típico de la masonería venezolana de la primera mitad del siglo XIX. Fue un ilustre prócer de la Independencia, participó en varias acciones militares junto a Bolívar ${ }^{48}$ y Páez, incluyendo la Batalla de Carabobo ${ }^{49}$. Su firma aparece en el acta constitutiva de la Gran Logia de Venezuela (1838) con el cargo de Gran Maestro de Ceremonias. Sus restos reposan en el Panteón Nacional, inaugurado durante el Gobierno de Guzmán Blanco en 1875.

A su muerte, acaecida en septiembre de 1848, le fueron celebrados unos honores fúnebres cuya descripción fue publicada, como era la regla en la masonería venezolana, en un folleto ${ }^{50}$. Este contiene, además de la descripción, los discursos pronunciados por las dignidades invitadas. En la descripción de la ceremonia, luego del discurso del representante del Consejo Supremo Confederado de los 33 Grados, se lee lo siguiente: "Continuando los trabajos con el ceremonial antes sancionado por la $\mathrm{R} \therefore \mathrm{L} \therefore$ fueron cantadas

\footnotetext{
${ }^{45}$ Atanasio Bello Montero, otro celebre músico venezolano, alcanzó, antes que Velásquez, el grado $32^{\circ}$, pero Montero era, además de músico, miembro del ejército y un prócer, pues había participado en la Guerra de Independencia.

${ }^{46}$ Tanto Velásquez como Bello Montero pertenecían a la clase social colonial de los pardos libres.

${ }^{47} J o s e ́$ María Velásquez y Francisco Conde, "Cantico Fúnebre" [partitura manuscrita] Colección Archivo Audiovisual de la Biblioteca Nacional de Venezuela. Cota JAL 146, Caracas, circa 1848.

${ }^{48}$ Es curioso constatar que Bolívar, cuya pertenencia a la masonería está documentada de forma muy escueta y que emitió un polémico decreto en 1828 prohibiendo las sociedades y confraternidades secretas en toda Colombia, estuvo rodeado constantemente por masones, tanto en el ámbito militar como en el mundo civil.

${ }^{49}$ Esta batalla selló la Independencia de Venezuela el 24 de junio de 1824. Carabobo integra, junto con Boyacá, Pichincha, Junín y Ayacucho, la pentalogía de las batallas del ciclo Bolivariano.

${ }^{50}$ Honores Fúnebres al M $\therefore$ Y $\therefore$ H.: Juan José Conde Ven $\therefore$ Maest $\therefore$ de la R $\therefore$ L $\therefore$ Concordia $\mathrm{N}^{\circ} 6$ [folleto], Caracas, 1848.
} 
en cierto acto por uno de los hh $\therefore$ que componían la orquesta, las siguientes Plegarias",51 y a continuación aparece un extenso poema escrito en octavas de arte menor ${ }^{52}$. El autor de las plegarias no está identificado en el texto, pero sabemos, por la partitura manuscrita del Cántico, que su autor es Francisco Conde. De las once estrofas que forman el poema, Velásquez puso música a solo cinco. Diecinueve años más tarde, el 9 de marzo de 1867, el poema fue nuevamente publicado, esta vez en el quincenario La Revista Mazónica ${ }^{53}$.

Francisco Conde fue un abogado y político caraqueño, hijo del prócer homónimo. No sabemos si tenía una relación de parentesco con Juan José Conde, pero es probable que sí, puesto que tanto Juan José, como los dos Franciscos, habían nacido en Caracas. Ocupó varios cargos ministeriales en diferentes gobiernos, incluidos los del general Páez ${ }^{54}$. En una carta de Atanasio Bello, a quien ya hemos nombrado, se le identifica como autor de la letra de unas plegaria compuestas por él ${ }^{55}$. Atanasio Bello lo llama "Panchito ${ }^{56}$ Conde", y como anexo de la carta incluye el texto de estas plegarias, que es diferente de las dedicadas a Juan José Conde.

Atanasio, a través de esta misiva, estaba entregando a Isaac Pardo, Venerable Maestro de la conocida logia caraqueña Esperanza, varias piezas de música. Una de ellas, llamada Para dar la Luz, es una transcripción de varios fragmentos de la ópera Norma de Bellini $^{57}$. Desafortunadamente la música de las plegarias de Atanasio no ha podido ser localizada. En cambio la partitura manuscrita de Para dar la Luz, forma parte de la colección de música de la Biblioteca Nacional. Vemos, a través de estos ejemplos, como los compositores masones estaban compenetrados con la ópera desde muy temprano en el siglo XIX.

Las Plegarias a Juan José Conde están llenas de referencias simbólicas masónicas (ver apéndice 1). En ellas se nombra a Hiram, a la acacia, al compás, al Gran Arquitecto, a la cadena y a las columnas. Francisco Conde estaba afiliado a la logia Concordia, al igual que Juan José, suponemos que trabajaron en este taller simultáneamente, pues en un cuadro logial de1850, a dos años de la muerte de Juan José, Francisco aparece con el grado $33^{\circ}$ y el Cargo de Venerable Maestro ${ }^{58}$. No sabemos a que logia estaba afiliado ni que grado poseía José María Velázquez al momento de la muerte de Juan José Conde, pero

\footnotetext{
${ }^{51}$ Honores Fúnebres al M $\therefore$ Y $\therefore$ H $\therefore$ Juan José Conde, 6.

${ }^{52}$ La octava de arte menor es una de las variantes de la estrofa castellana de ocho versos octosílabos.

${ }^{53}$ La Revista Mazónica, "Plegarias" (9 de marzo de 1867), 63.

${ }^{54}$ Elke Nieschulz de Stockhausen, "Francisco Conde", en Diccionario de Historia de Venezuela.

${ }^{55}$ López Maya, "Música y Masonería en la Venezuela del siglo XIX”, en musicaenclave (2009 [citado el 16 de junio de 2016]): disponible en http://www.musicaenclave.com/vol-4-1-enero-abril-2010/

${ }^{56}$ Panchito es un hipocorístico con diminutivo que se usa en Venezuela para el nombre Francisco.

${ }^{57}$ Atanasio Bello Montero, Para dar la Luz [partitura manuscrita], Colección Archivo Audiovisual de la Biblioteca Nacional, Cota JAL 44, 1862.

${ }^{58}$ Cuadro de las Dig.: Ofic.: y demás miembros de la $\mathrm{R} \therefore \mathrm{L} \therefore$ Concordia $\mathrm{n}^{\circ} 6$.
} 
suponemos que aún seguía en América y que ostentaba un grado superior, tal vez el $30^{\circ}$ o $31^{\circ}$.

\section{El Cántico Fúnebre}

El canto de plegarias parece haber sido una parte obligatoria en los ritos funerarios masónicos durante el siglo XIX pues hay abundante documentación sobre este particular. Información acerca de esto aparece, sobre todo, en los folletos descriptivos de ceremonias fúnebres. Como ya hemos mencionado, las referencias más antiguas al canto de plegarias las constituyen la partitura del Cántico de Velásquez (1848) y las Plegarias de Francisco Conde publicadas dentro del folleto que describe los funerales de Juan José Conde (1849). También hay un poema titulado "plegarias" en un folleto publicado a raíz de la muerte de Ramón Hernández Bello en $1850^{59}$. Bello era miembro de la logia Unión $n^{\circ} 5$, una de las más antiguas en Venezuela. En otro folleto, dedicado a los funerales del prócer Santiago Mariño, se menciona el canto de una plegaria, aunque no está publicado ningún poema $(1854)^{60}$.

La muerte de Diego Bautista Urbaneja, prócer y padre fundador de la masonería venezolana, representa un hito importante en el desarrollo de las tenidas funerarias. En el folleto correspondiente a sus funerales $(1856)^{61}$ se menciona la ejecución de "una hermosa y sentida plegaria” (pág. 5) y además se explica, en un apéndice, que a raíz de este acontecimiento “(...) el Soberano Gran Comendador y algunos jefes masónicos juzgaron ser llegada la ocasión, como sucede en otros Orientes extranjeros, de permitir al mundo profano la visita de sus Templos, para desvanecer las preocupaciones del vulgo (...)” (pág. 22). Esta iniciativa debe haber tenido un éxito notable, pues el redactor menciona que más de seis mil personas visitaron el local en las siguientes cuarenta y ocho horas en las que el Templo se mantuvo abierto. Es posible que esto sea una exageración, pero lo cierto es que, a partir de entonces, las tenidas funerarias pasaron, de ser rituales o cerradas, a ser blancas o abiertas al público.

Ya para la década de 1880 las tenidas fúnebres se habían convertido en espectáculos públicos en donde se daba cita lo más selecto de la "sociedad". Reseñas sobre estas magníficas tenidas aparecen en la prensa masónica y regular. El lugar de las plegarias está muchas veces ocupado por conocidas arias de ópera y los mejores cantantes de la ciudad se presentan en los templos. En 1885, en los funerales de Francisco Filomena, Gran Maestro de la logia caraqueña Sol de América, se canta el aria Pietà, Signore, en el momento

\footnotetext{
${ }^{59}$ Honores Fúnebres del Perf.: Cab.: Ramón Hernández Bello [folleto],Caracas: Imprenta de George Corser.

${ }^{60}$ Honores Fúnebres Tributados por La M $\therefore$ R $\therefore$ G $\therefore$ L $\therefore$ de la Rep $\therefore$ de Ven $\therefore$ Al M $\therefore$ I $\therefore$ H $\therefore$ General Santiago Mariño Ser.: Gr.: Maest.: Del Gr.: Or.: Nacional [folleto], Caracas: Imprenta de George Corser, s.a.

${ }^{61}$ Honores Fúnebres Tributados a la Grata Memoria del M $\therefore$ Il $\therefore$ H $\therefore$ G $\therefore$ I $\therefore$ G $\therefore$ Gr $\therefore$ 33. Sermo $\therefore$ Gr $\therefore$ Mtre $\therefore$ del Gr:: Or.: Nac.: Diego Bta. Urbaneja [folleto], Caracas: Imprenta y Librería del Teatro de Legislación, s.a.
} 
correspondiente a la plegaria $^{62}$. Pietà, Signore es una famosa pieza del repertorio litúrgico católico escrita por Alessandro Stradella, un compositor italiano del siglo XVII. La reseña aparece en el propio periódico de Sol de América y en otros dos periódicos caraqueños. En 1890, en el marco de la Gran Tenida Fúnebre, ofrecida por el Gran Oriente Nacional en el Día de los Muertos, se canta nuevamente Pietà, Signore en el momento de las plegarias. La ceremonia es dirigida por el Gran Maestro de Venezuela y presidente de la República en ejercicio, Raimundo Andueza ${ }^{63}$. De esta manera, el repertorio masónico se enriqueció aún más, al incorporar música católica. Algo paradójico, si se piensa que la masonería y la Iglesia estaban en conflicto y el solo hecho de ser masón acarreaba la excomunión.

El Cántico de Velásquez fue escrito antes de la transformación de las tenidas fúnebres en tenidas blancas. Sin embargo, al analizar su estructura y su estilo nos percatamos de que, no solo evidencia la influencia de la ópera italiana del primer tercio del siglo XIX, sino que además Velásquez demuestra un alto nivel de maestría y originalidad. La obra está escrita para una plantilla de tenor solista, una flauta, dos cornos y cuerdas. Está agrupación fue la más utilizada en la música sinfónica venezolana durante la primera mitad del siglo XIX y buena parte de la segunda. Desde el punto de vista técnico, tanto en la parte de tenor como las instrumentales, se evidencia que los músicos que participaron en su interpretación estaban habituados a tocar en las numerosas óperas que se representaban en Caracas para ese entonces ${ }^{64}$.

La obra está estructurada en dos grandes partes, la primera de las cuales contiene a su vez cuatro sub-secciones: Recitativo, Molto, Recitativo y Maestoso. La segunda parte contiene dos sub-secciones: Moderato y Allegro. Los dos Recitativos de la parte inicial se corresponden con el llamado recitativo accompagnato del siglo XIX, en el cual el solista hace una especie de "declamación cantada" de ritmo libre y con pequeñas intervenciones de la orquesta que sirven para subrayar el contenido dramático del texto ${ }^{65}$. La sección llamada Molto, puede ser considerada un arioso; una sección ubicada, generalmente, en medio de un recitativo y que es igual a este pero sin la libertad rítmica y con mayor participación de la orquesta ${ }^{66}$. El Maestoso, con el que culmina la primera parte, es más melodioso y la parte de orquesta es más densa, tiene el estilo de un aria propiamente dicha.

${ }^{62}$ La Estrella Flamigera (20 de mayo de 1885), 280.

${ }^{63}$ El Sol de América (17 de diciembre de 1890), 340.

${ }^{64}$ Recordemos que en 1848 , cuando se realiza la ceremonia aludida, todavía las tenidas fúnebres eran rituales, de modo que todos los músicos que participaron en ella han debido ser forzosamente masones.

${ }^{65}$ (Budden, Recitative after 1800 2008). Julian Budden, Recitative after 1800, en Grove Music Online (2008 [citado el 16 de junio de 2016]): disponible en file://G:/Grove/Entries/S23019.htm

${ }_{66}^{6}$ (Budden, Carter, y otros 2008). Julian Budden; Tim Carter, Marita McClymonds, Margaret Murata, Jack Westrup, Arioso, en Grove Music Online (2008 [citado el 16 de junio de 2016]): disponible en file:///G:/Grove/Entries/S23019.htm 
El Moderato, tiene las características de la cavatina de los siglos XVIII y XIX. La cavatina se define como una pequeña pieza intercalada dentro de una obra mayor ${ }^{67}$. El Moderato, que hace las veces de cavatina en el Cántico, es muy particular, pues está escrito en un ritmo bailable que nos recuerda a una tarantela. En el Allegro final se retoma el estilo y el carácter del Maestoso, pero a una velocidad más rápida. En esta última parte el tenor es exigido técnicamente, a la manera del bel canto que se popularizó en el siglo XIX gracias a los compositores Rossini, Bellini y Donizetti.

Todos estos elementos; el recitativo accompagnato, el arioso, la cavatina y el bel canto, son muy comunes en las óperas italianas de Rossini y Bellini, las cuales eran interpretadas frecuentemente en la Caracas que le tocó vivir a José María Velásquez. Su originalidad y maestría se expresan en la forma como organizó sintácticamente las seis subsecciones, creando un contraste de velocidad y carácter entre la primera parte y la cavatina, y estableciendo un poderoso clímax en el allegro final. Para este fin usó la velocidad del fragmento y el virtuosismo de la parte cantada. La pieza completa tiene una duración aproximada de seis minutos, de modo que los numerosos cambios que posee acentúan la sensación de contraste, algo que también es característico de la ópera italiana de la época y que Velásquez supo usar con pericia.

Imagen 2

Manuscrito de Cántico Fúnebre José María Velásquez (detalle)

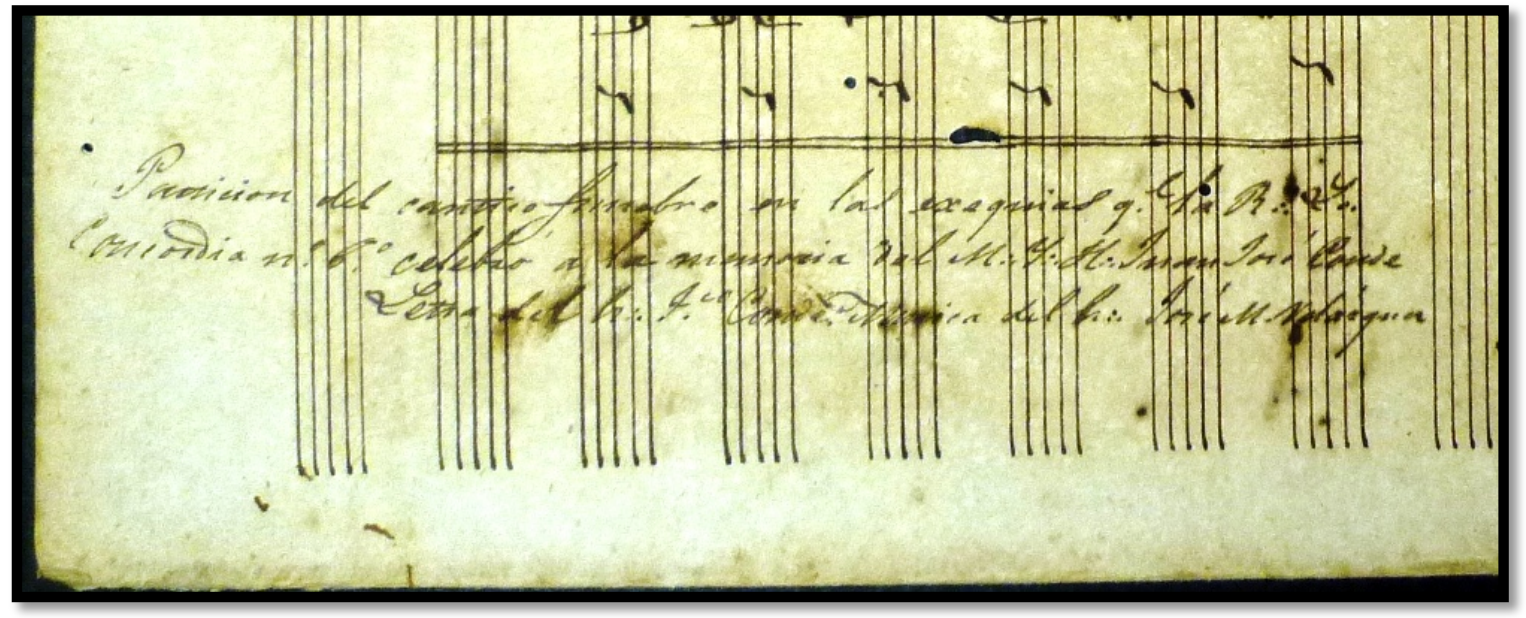

Fotografía de Juan de Dios López Maya.

El Cántico no es la única plegaria fúnebre masónica que pertenece a la colección de la Biblioteca Nacional. Existe otra, de características muy similares, titulada Plegarias en

${ }^{67}$ Tim Collins, Cavata, en Grove Music Online (2008 [citado el 16 de junio de 2016]): disponible en file:///G:/Grove/Entries/S23019.htm 
las Exequias del H:. Manuel Ma. Poleo ${ }^{68}$. Su autor es un músico venezolano muy poco conocido llamado Casimiro Arias. El manuscrito no está fechado, pero suponemos que debe haber sido escrito entre 1859 y 1863 , pues Poleo, que pertenecía a la logia caraqueña Esperanza, aparece por última vez en el cuadro logial de 1859 y luego desaparece en 1863; los cuadros de Esperanza, correspondientes a 1860, 1861y 1862, no pudieron ser ubicados en el transcurso de esta investigación. Poco sabemos de la vida de Poleo, pero parece haber estado vinculado con la actividad teatral. La letra de estas Plegarias, pertenece a Felipe Estévez, otro prócer masón de primer orden que ocupó cargos clave en la armada independentista.

Estructuralmente y estilísticamente las Plegarias son muy parecidas al Cántico. Un arioso inicial se conecta con una cabaletta a través de un recitativo. La cabaletta, en la ópera del siglo XIX, se define como la última parte de un aria en dos partes, y es generalmente más rápida que la primera ${ }^{69}$. La cabaletta de las Plegarias es sorprendentemente parecida a la cavatina del Cántico de Velásquez.

Otro aspecto en común que tienen ambas obras es la utilización de simbología masónica musical. Es generalmente aceptado que Wolfgang Amadeus Mozart creó dicha simbología y la utilizó abundantemente en sus obras masónicas y no masónicas. Uno de los recursos más conocidos de dicha simbología es la llamada "tonalidad masónica"; esta se expresa a través de un símbolo llamado "armadura de clave de Mi bemol" que es el equivalente musical de los tres puntos de la abreviatura masónica tripunteada. Tanto el Cántico como las Plegarias utilizan este recurso.

\section{Imagen 3}

Armadura de clave y abreviatura tripunteada

Armadura de clave de Mi bemol: $\frac{\frac{b_{b}}{b_{6}}}{\therefore}$
Abreviatura tripunteada:

La muerte de Juan José Conde, prócer y fundador del Gran Oriente, ameritaba la colaboración de Velásquez, uno de los músicos más importantes de la ciudad, y Francisco Conde, un hombre de letras y político destacado. No es descartable sin embargo, que en otras tenidas fúnebres se comisionara a algún músico para escribir unas plegarias especialmente dedicadas al difunto.

\footnotetext{
${ }^{68}$ Casimiro Arias, "Plegarias en las exequias del h.: Manuel María Poleo (letra del h.: Felipe Estévez)" [partitura manuscrita] (s.f.), Caracas: Colección de música de la Biblioteca Nacional de Venezuela, Cota JAL 147.

${ }^{69}$ Tim Collins, Cavata.
} 
Desafortunadamente no conocemos, por haber sido destruidas las actas de Concordia $^{70}$, quienes fueron los músicos que interpretaron el Cántico, pero revisando los cuadros logiales caraqueños de la época podemos hacer algunas suposiciones: en primer lugar, creemos que el propio Velásquez, que era cantante, fungiera como tenor solista. También es posible que Atanasio Bello y su primo Bernardino Montero, estuviesen entre los instrumentistas. El flautista era posiblemente Juan José Tovar y otros músicos conocidos como Juan Bautista Abreu y los hermanos Juan Bautista y Eduardo Calcaño también deben de haber participado. Era, si es acertada nuestra suposición, una columna de armonía de lujo, integrada por los mejores músicos con que contaba la ciudad.

\section{Conclusiones}

El Cántico Fúnebre de José María Velásquez es solo la punta de un iceberg. Muchas obras con estas características y este destino deben haber sido interpretadas en Venezuela y seguramente en otras logias de otras naciones de nuestro continente. Una revisión de los archivos logiales con el objetivo de conseguir otras composiciones similares es necesaria, tanto para la musicología como para la masonería. Se trata de un patrimonio que enriquecería notablemente el conocimiento de nuestro siglo XIX.

Un masón, y su familia, se consideraban honrados si en sus funerales se interpretaba una composición especialmente dedicada a él con las características de un aria. Lo común era que cualquier ceremonia estuviera "solemnizada"71 con extractos de conocidas óperas y que la teatralidad propia de ellas influyera en la puesta en escena de la ceremonia en sí. El masón venezolano del siglo XIX era considerado un prohombre, y entre sus muchas virtudes, debían estar, idealmente, la filantropía activa, el conocimiento y amor por la ópera y la música en general, la participación política, la defensa del modelo republicano y la erudición. Este modelo encaja admirablemente bien con el comportamiento liberal y la ilustración "ecléctica", propias de las clases altas y medias de nuestras sociedades en aquel entonces.

En el apéndice de este artículo hemos colocado el poema completo de Francisco Conde. En él están admirablemente plasmadas las cualidades anteriormente mencionadas. Juan José Conde es descrito, en este poema, como el héroe masón liberal y la música de Velásquez, cargada de pathos, subraya la intención del texto y producen una simbiosis con un alto potencial de herramienta proselitista. Pocos años más tarde, con la apertura de la masonería al mundo profano y el advenimiento del Partido Liberal en el poder, la masonería venezolana haría uso efectivo de esta herramienta heredada de sus hermanos de

\footnotetext{
${ }^{70}$ Reverón, Cisma masónico, 23.

${ }^{71}$ Esta es la expresión más comúnmente usada en los documentos masónicos para referirse al uso de música en las tenidas.
} 
la generación anterior. Muchos de los cuales, como el propio Velásquez que murió en 1883, tuvieron la dicha de vivir para verla en acción.

\section{Fuentes}

«Almanaque para el año de 1851: arreglado para el meridiano de Caracas.» Caracas: Imprenta de George Corser, 1851.

Arias, Casimiro. «Plegarias en las exequias del h.: Manuel María Poleo (letra del h.: Felipe Estévez) [partitura manuscrita].» Caracas: Colección BNV cota JAL 147, s.f.

Bawden, Olga Beatríz. «San Juan al Mundo.» Arturo Beruti, un músico expecional. mayo de 1964.

Bello Montero, Atanacio. «Para dar la Luz [partitura manuscrita“].» Caracas: Colección del Archivo Audiovisual de la Biblioteca Nacional de Venezuela. Cota JAL 44, 1862.

Budden, Julian. «Recitative after 1800.» Grove Music Online. 2008.

Budden, Julian, Tim Carter, Marita McClymonds, Margaret Murata, y Jack Westrup. «Arioso.» Grove Music on line. 2008.

Calcaño, José Antonio. La Ciudad y su Música. Caracas: Ediciones de la Biblioteca de la Universidad Central de Venezuela, 2001.

Capelán Fernández, Montserrat, y Roberto Ojeda Tovar. Motetes, Canciones y Tonos de Atanacio Bello Montero. Caracas: Fundación Vicente Emilio Sojo, 2012.

Castellón, Hello. Guía Histórica de la Masonería en Venezuela. Caracas: Lito Jet, 1985.

Colin, Tims. «Cavata.» Grove Music on line. 2008.

Cotte, Roger. La Musique Maconnique et sus Musiciens. Braine-le Comte: Editions du Baucens, 1975.

«Cuadro de las DD $\therefore$ Ofic $\therefore$ y demás miembros de la Resp $\therefore$ Log.: América $\mathrm{n}^{\circ} 17$ en el año de 1849.» Sección Arístides Rojas. Academia Nacional de la Historia. Caracas, 1849.

«Cuadro de las DD $\therefore$ Ofic $\therefore$ y demás miembros de la Resp. Log. Prudencia ${ }^{\circ} 40$, al Or $\therefore$ de Caracas en el año de 1856.» (Colección de Juan de Dios López Maya). Caracas, 1856.

«Cuadro de las DD $\therefore$ OOf $\therefore$ y demás miembros de la Resp $\therefore$ Log.: Regeneración $\mathrm{N}^{\circ} 40$ al Or $\therefore$ de Caracas.» Caracas, 26 de octubre de 1882.

«Cuadro de las Dig.: Ofic $\therefore$ y demás miembros de la $\mathrm{R} \therefore$ L $\therefore$ Concordia $\mathrm{n}^{\circ}$ 6.» Caracas: Sección de Libros Raros de la Biblioteca Nacional de Venezuela, 16 de junio de 1850.

«Discurso Traz $\therefore$ en la Instal $\therefore$ del Gr.: Or $\therefore$ Nac..$»$ Caracas: Academia Nacional de la Historia, Archivo, 6 de abril de 1856. 
Documentos sobre músicos coloniales venezolanos. Caracas: Sección de Libros raros de la Biblioteca Nacional de Venezuela. Cota MSV CBY5620, 1794-1836.

El Sol de América. «Honores Fúnebres.» 17 de diciembre de 1890: 340.

El Sol de América. «Honores Fúnebres celebrados por el Grande Oriente Nacional.» 1 de diciembre de 1891: 6-7.

El Sol de América. «Instalación del GR $\therefore$ OR $\therefore$ NAC $\therefore$ de los EEUU de Venezuela.» 24 de junio de 1891: 1-2.

Ferrer Benimelli, José Antonio. Bibliografia de la Masonería. Caracas: Universidad Católica Andrés Bello, 1974.

Ferrer Benimelli, José Antonio. «Masonería.» En Diccionario de Historia de Venezuela, 75-78 V.3. Caracas: Fundación Polar, 1997.

Figueroa, Adrian. «Crónica.com.mx.» Hallan diez partituras inéditas del compositor Aniceto Ortega. 13 de abril de 2010.

Guzmán, Antonio Leocadio. «Junta Directiva del Centenariodel Libertador $\mathrm{n}^{\circ} 400 . »$ Archivo General de la Nación. Centenario del Libertador. Legajo 2, página 2. 20 de enero de 1883.

Honores Fúnebres al M $\therefore$ Y $\therefore$ H $\therefore$ Juan José Conde Ven $\therefore$ Maest $\therefore$ de la $R \therefore$ L $\therefore$ Concordia $N^{\circ}$ 6 [folleto]. Caracas, 1848.

Honores Fúnebres del Perf: Cab. Ramón Hernández Bello [folleto]. Caracas: Imprenta de George Corser, 1850.

Honores Fúnebres Tributados a la Grata Memoria del M $\therefore$ Il $\therefore$ H $\therefore$ G $\therefore$ I $\therefore$ G $\therefore$ Gr $\therefore 33$. Sermo $\therefore$ Gr: Mtre: del Gr: Or:: Nac: Diego Bta. Urbaneja [folleto]. Caracas: Imprenta y Librería del Teatro de Legislación, 1856.

Honores Fúnebres Tributados por La M $\therefore$ R $\therefore G \therefore L \therefore$ de la Rep $\therefore$ de Ven $\therefore$ Al M $\therefore I \therefore H \therefore$ General Santiago Mariño Ser:Gr:Maest:: Del Gr:: Or:: Nacional [folleto]. Caracas: Imprenta de George Corser, 1854.

INBA. Boletín 483. 9 de abril de 2014.

Joglar, Hugo Roca. «Pro Opera.» La Partenope de Manuel de Sumaya. Noviembrediciembre de 2011.

La Estrella Flamígera. «Honores Fúnebres.» 20 de mayo de 1885: 280.

La Redacción. «Duelo a la memoria del M $\therefore$ I $\therefore$ H $\therefore$ Gr $\therefore$ Insp. Gral $\therefore$ José MaríaVelásquez.» La Abeja, $1^{\circ}$ de enero de 1884: 237-238.

La Revista Mazónica. «Plegarias.» 9 de marzo de 1867: 63.

«Libro Quinto de anotación de bautismos administrados en esta Iglesia Parroquial de la Santa Cruz y la Candelaria.» Caracas: Archivo Arquidiocesano de Caracas, 1794. Folios 140V-141 R.

Londoño Vega, Patricia. «Las Colombianas durante el siglo XIX.» Biblioteca Virtual Luis Ángel Arango. s.f. 
López Maya, Juan de Dios. "Columnas de Armonía. La tradición musical masónica del siglo XVIII y su reflejo en las logias venezolanas del siglo XIX”. Ponencia presentada en el VIII Congreso Nacional de Musicología. Logroño: Sociedad Española de Musicología, 2012.

López Maya, Juan de Dios. "El Cuaderno de Música de José Antonio Páez”. El Desafio de la Historia 5, no. 31 (s.a.): 22-25.

López Maya, Juan de Dios. "Esperanza n7 (1854-1869). Quince años en la vida musical de una logia caraqueña”. Anuario GHRIAL 6 (2012): 173-204.

López Maya, Juan de Dios. "Música y Masonería en la Venezuela del siglo XIX". En musicaenclave, 2009.

Melanie Plesch, Geranrdo Huseby. "La música argentina en el siglo XX”. Colección Nueva Historia Argentina. 2014.

Michelena, Carmen. «Historia para compartir.» la Influencia Francesa en la Caracas del siglo XIX. 14 de mayo de 2011.

Montero, José Ángel. Virginia. Tragedia Lírica en Cuatro Actos [folleto]. Traducido por Ramón Sánchez. Caracas: Imprenta de la Opinión Nacional, 1873.

Montero, José Angel, y Francisco Tosta García. Doña Irene o la política en el hogar [folleto]. Caracas: Imprenta de la Concordia, 1876.

Música Antigua. «Músicaantigua.com.» la Purpura de la Rosa; la primera ópera de América. 20 de diciembre de 2012.

Nieschulz de Stockhausen, Elke. «Francisco Conde.» En Diccionario de Historia de Venezuela. Caracas: Fundación Empresas Polar, 1997.

Peñín, José. «Osorio, José María.» Enciclopedia de la Música en Venezuela. Fundación Bigott, 1998.

Pérez Perazzo, Jésus Ignacio. El Maravilloso Mundo de la Banda. Caracas: Cuadernos Lagoven, 1989.

Ramírez, María. El otoño luminoso de Isaac Pardo. Caracas: Monte Avila, 1999.

Reverón, Eloy. Cisma masónico, Caín y Abel son hermanos. Caracas: IVEM, 1996.

Reverón, Eloy. El Fantasma de Bolivar en la masoneríavenezolana. Caracas: IVEM, 2001.

Ruíz, Anibal. Boceto biográfico del Maestro Federico Villena. Caracas: s/e, 1898.

Saingiorgi, Felipe. «Rodríguez Bruzual, Benigno.» En Enciclopedia de la Música en Venezuela, 548. Caracas: Fundación Bigott, s/a.

Scaraveli, Gisele. «Revista Regional.» Elias Lobo, um ituano imortal. s.a.

van Praag, Leon. Guía o Directorio Anual de Caracas. Caracas: Tipografía El Cojo, 18911892.

Velásquez, José María, y Francisco Conde. «Cantico Fúnebre [partitura manuscrita].» Caracas: Colección Archivo Audiovisual de la Biblioteca Nacional de Venezuela. Cota JAL 146, circa 1848. 
Zárate Toscano, Verónica, y Serge Gruzinsky. «UAEM Redalyc.org.» Opera, imaginación y sociedad. México y Brasil, siglo XIX. Historias conectadas: Idelgonda de Melesio Morales e Il Guarany de Carlos Gomes. octubre-diciembre de 2008.

\section{Bibliografía}

Arráiz Lucca, Rafael. Venezuela 1830 a nuestros días. Caracas: Alfa, 2007.

Attali, Jacques. Ruidos, ensayo sobre la economía política de la música. México: Siglo XXI, 1995.

Briceño, Jipson. Los templos Masónicos de Venezuela en el siglo XIX. Caracas: Fundación Sol de América, 2014.

Calcaño, José Antonio. La Ciudad y su Música. Caracas: Ediciones de la Biblioteca de la Universidad Central de Venezuela, 2001.

Caldwell, John. Editing Early Music. Oxford: Oxford University Press, 1995.

Caraci Vela, Maria. La Filologia Musicale. Istituzioni, storia, strumenti critici. Vol. I. 3 vols. Lucca: Libreria Musicale Italiana, 2005.

Carnicelli, Américo. La Masonería en la Independencia de América 1810-1830. 2 vols. Bogotá: Corporación Nacional de Artes Gráficas, 1970.

Cassard, Andrés. Manual de la Masonería o sea Tejador de los Ritos Antiguo Escoces, Francés y de Adopción. Nueva York, 1860.

Consalvi, Simón Alberto. «La política exterior de Venezuela durante la época de Antonio Guzmán Blanco.» En Los tiempos envolventes del guzmancisco, 199-223. Caracas: Fundación John Boulton y UCAB, 2011.

Cotte, Roger. La Musique Maconnique et sus Musiciens. Braine-le Comte: Editions du Baucens, 1975.

de Armas Chitty, José Antonio. Vida política de Caracas en el siglo XIX. Caracas: Ministerio de Educación, 1969.

de la Plaza, Ramón. Ensayos Sobre el Arte en Venezuela. Caracas: Ediciones de la Presidencia de la República, 1977.

Gran Logia de la Rpública de Venezuela. Liturgias, Texto Oficial. Caracas, 2003.

Grier, James. The Critical Edition of Music. Cambridge: Cambridge University Press, 1996.

Henry, Jacques. Mozart the Freemason. Rochester: Inner Traditions International, 1997.

Hernández González, Manuel. Liberalismo, masonería y cuestión nacional en Cuba 18081823. Tenerife: Ediciones Idea, 2012.

Historie, obligations et satuts de la tres venerable confraternite des francsmacons. Francfort: Varrentrapp, 1742.

Kühn, Clemens. Tratado de la Forma Musical. Huelva: Idea, 2003. 
Lawson, Colin, y Stowell Robin. La Interpretación Histórica de la Música. Madrid: Alianza Música, 2005.

Meyer, Leonard. Style and Music. Theory, History an Ideology. Philadelphia: University of Pennsilvania Press, 1989.

Nattiez, Jean-Jacques. Music and Discourse. Toward a Semiology of Music. Princeton: Princeton University Press, 1990.

Reverón, Eloy. El Fantasma de Bolívar en la masoneríavenezolana. Caracas: IVEM, 2001.

Rodríguez, Fidel. Caracas, la vida musical y sus sonidos (1830-1888). Caracas: Fondo Editorial de la Contraloría General de la República, 1999.

Viña, José Ángel. «Música y Caridad. Conciertos benéficos en la Caracas del siglo XIX.» musicaenclave revista venezolana de musicología. 2010. http://www.musicaenclave.com/vol-4-3-septiembre-diciembre-2010/ (último acceso: 17 de julio de 2013). 


\section{Anexo 1}

Plegarias, por Francisco Conde (en letras cursivas hemos señalado las estrofas utilizadas por Velásquez en el Cántico Fúnebre)

\section{PLEGARIAS}

Esos lúgubres crespones

Que enlutan el Templo Santo

Húmedos están de llanto

Por la luz que se apagó;

Porque la logia "Concordia"

Tiene menos una vida

Una columna caída

Que inmenso vago dejó

Que el Maestro Venerable

De acacia inmortal cubierto

El sueño duerme del muerto

Allá en la tumba de Hiram

Mientras aquí los obreros

Con sus usos inmortales

Cantan himnos funerales

Que su loza romperán

A lado de Hiram descansa

Con la Acacia por delante

Quien fue virtuoso, constante,

$Y$ fiel y firme al deber

El cruel rayo de la muerte

Hirió el pecho a nuestro hermano

El trueno sonó lejano

$Y$ se estremeció el taller

Lloremos al Venerable

Que en su terrestre destino

Siempre transitó el camino

Del bien y la caridad;

Que en el taller "La Concordia"

Los obreros de su templo 
Seguirán siendo su ejemplo

De firmeza y de lealtad

Llevemos hasta su tumba

Nuestros himnos funerales

Y los llantos fraternales

Rieguen la acacia inmortal

Que colgada en los espacios

Estará nuestra plegaria

Cual lámpara funeraria

Pendiente en célico umbral

En derredor de su túmulo Alzemos un humo denso

Columnas de suave incienso

Que se eleven hasta Dios

Y sus insignias mazónicas

Con sus prendas militares

Decorando los altares

En el templo están las dos

Falta en el templo un obrero,

Falta una luz, una estrella

Que hermoso fulgor destella

En la celeste mansión

Rompió nuestra cadena

De Jehová por los arcanos

$Y$ falta entre los hermanos

Un Venerable varón

Por eso están los mazones

Siguiendo el dogma sagrado

Dentro del círculo trazado

Por las líneas del compás;

Por eso buscan ansiosos

La rectitud por lucero

La justicia por sendero

Para no variar jamás 
¡Bendito sea el hermano!

Que así deja la existencia

Limpia y bella la conciencia

Pura y sagrada la fe;

A quien el Grande Arquitecto

Del misterioso Universo, Condujo a un mundo diverso

Del triste mundo en que fue

Aquí viven sus memorias

Allá viven sus despojos

$Y$ el llanto de nuestros ojos

Revela nuestro pesar

Pues, en coro, los mazones

Con el alma asida al duelo

No tienen otro consuelo

Que el consuelo de llorar

Fuente: Revista Mazónica (9 de marzo de 1867): 63. 


\section{Anexo 2}

Lista de presidentes masones publicada por el quincenario Sol de América el 1 de mayo de 1891.

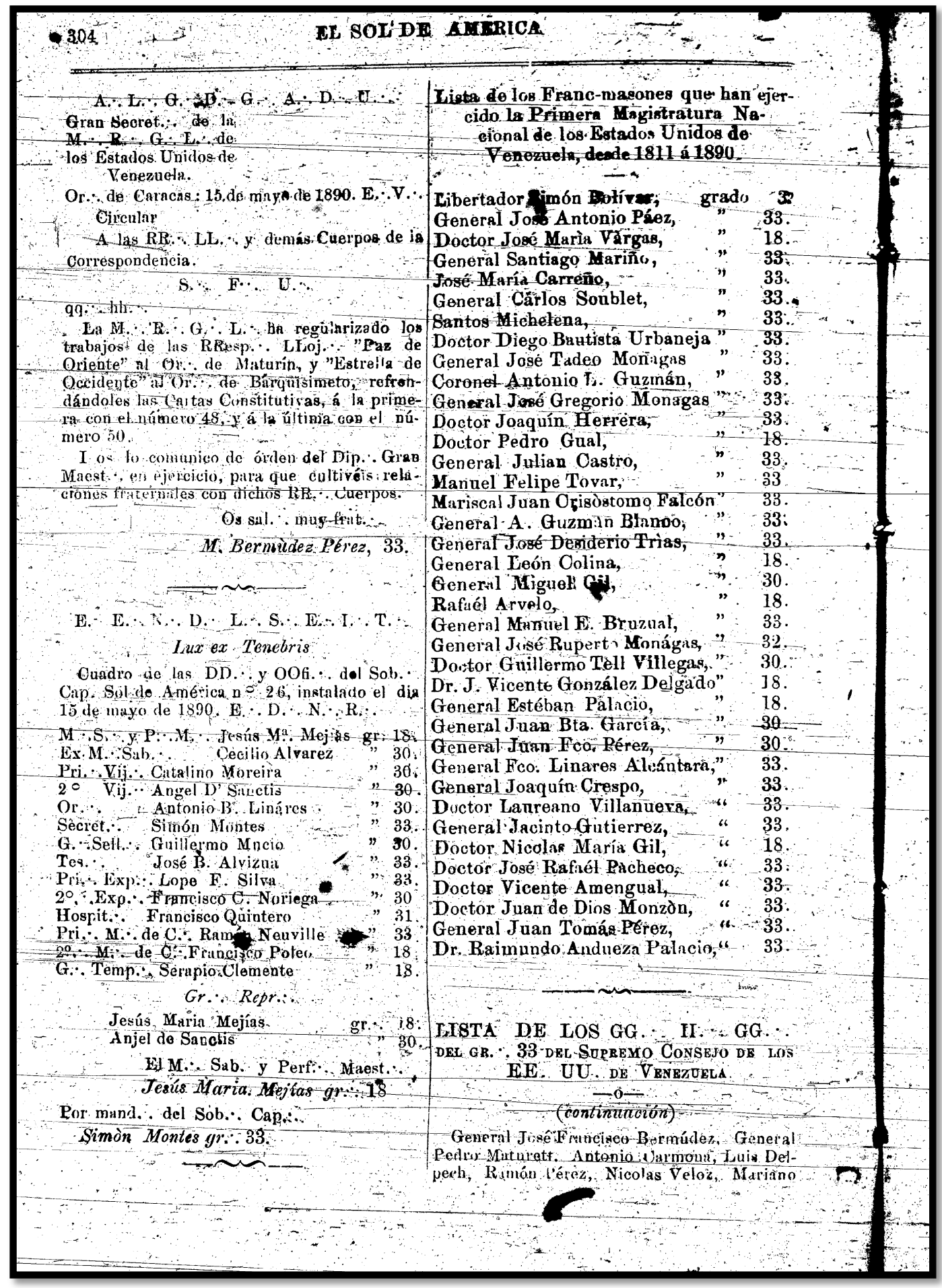

